\section{Diabetes Mellitus and Cancer}

In theory it should be a fairly easy matter to see whether there is any difference between diabetic and non-diabetic persons in their risk of developing cancers of various sites. In theory, also, differences one way or the other might be expected in view of Otto Warburg's ${ }^{1}$ observation that normal and tumour tissues differ in the way they metabolize glucose. In practice there are considerable difficulties. Criteria for the diagnosis both of diabetes and of cancer have to be defined, and in retrospective epidemiological studies it may be difficult to know whether or not particular criteria have been fulfilled and, if so, the ages at which they were first fulfilled in individual patients.

The fact that cancer and diabetes may occur together in the same patient has never been in serious doubt, ${ }^{2}$ and for many years an association between diabetes and cancer of the pancreas has been evident. A. Marble, ${ }^{3}$ as long ago as 1934 , reported the coincidence of cancer and diabetes in 256 out of 10,000 diabetics. Of the 256 cancers, $33(13 \%)$ were of the pancreas, a proportion that is much higher than seen in nondiabetics. An obvious explanation of an association between pancreatic cancer and diabetes would be destruction of islet cells by tumour, but experienced surgeons, such as Rodney Smith, ${ }^{4}$ regard diabetes mellitus as a rare complication of destruction of pancreas by tumour, for "even an extremely small amount of normal pancreas remaining will avoid this complication."

This was broadly the state of knowledge before the recent publication of Irving I. Kessler's study. ${ }^{5}$ Kessler ascertained the cancer mortality until 1959 among 21,447 patients registered at the large Joslin clinic for diabetes in Boston during the 26 years from 1930 to 1956 . Before June 1939 the diagnosis of diabetes was established by a venous blood sugar (Folin-Wu) of $130 \mathrm{mg}$. or more per $100 \mathrm{ml}$. blood (fasting) or $170 \mathrm{mg}$. or more per $100 \mathrm{ml}$. (after a meal), in association with glucosuria which was plainly related to diet. After June 1939 the critical fasting blood-sugar level was $140 \mathrm{mg}$. per $100 \mathrm{ml}$. The criteria for death from cancers and other causes were the entries on death certificates, coded according to the International List. ${ }^{6} 7$ Only patients who survived for at least one year after the first diagnosis of diabetes were included in the survey. The observed number of deaths from each cause was compared with the expected number, calculated from age- and sex-specific death-rate data published in the Annual Reports of the Vital Statistics of Massachusetts.

Among men with diabetes, death from cancer of all types occurred less frequently than expected. Deficiencies in deaths from cancers of the respiratory tract and of the rectum were partly responsible for this difference, the rest of which was mainly due to an increased risk of other causes of death, particularly diabetes itself and coronary heart disease. Despite the overall deficiency of cancer deaths in the male diabetics

1 Warburg, O., The Metabolism of Tumours. London, Constable, 1930. 2 Schäfer, O., Carcinom und Diabetes. Augsburg, Rösler, 1934.

3 Marble, A., New England fournal of Medicine, 1934, 211, 339.

- Smith, R., in Cancer, ed. R. W. Raven, Vol. 2, p. 186. London, Butterworths, 1958 .

5 Kessler, I. I., Fournal of the National Cancer Institute, 1970, 44, 673.

.S. Bureau of the Census, Manual of the International List of Causes of Death, 5th revision. Washington, D.C., U.S. Government Printing

World Health Organization, Manual of the International Statistical Classification of Diseases, Iniuries and Causes of Death, 7th revision. Geneva, World Health Organization, 1957.

- Sommers, S. C., Murphy, S. A., and Warren, S., Gastroenterology, 1954 27, 629.

- Ingle, D. J., Diabetes, 1965, 14, 93. they experienced the expected excess risk of death from pancreatic cancer.

Among women with diabetes, deaths from cancers of all types were only slightly, and not significantly, more numerous than expected. However, this overall comparison hides a significantly increased risk of pancreatic cancer and a significantly decreased risk of cancer of the uterus, both of the body and of the cervix.

The interpretation of the diminished risk of respiratory cancer in diabetic males in Kessler's survey is complicated by the fact that $17 \%$ of them were Jews as compared with only $5 \%$ of the control population. The genetic constitution of the Jew, which is known to favour the development of diabetes, might protect against respiratory carcinogens. Alternatively, cigarette smoking might have been more prevalent among the control population either because of its lower proportion of Jews or for some other reason. In any event, the low risk of cancer of the uterine body in the diabetic females cannot be due to an excessive representation of Jews since this form of cancer is more common in Jewish than in gentile women.

The elucidation of most of the complex problems raised by Kessler's findings must await the results of further studies. Only in the case of the positive association between diabetes and pancreatic cancer, which is unequivocal in both sexes, is it reasonable to proceed to the next level of inquiry-namely, a consideration of the mechanisms involved. The requirement that patients could be included in the survey only if they survived for more than one year after the diagnosis of diabetes reduced the likelihood of cancer of the pancreas being the antecedent disease. However, this possibility is not eliminated as a partial explanation, since in 11 out of the 78 cases the cancer was diagnosed within one year of the first diagnosis of diabetes. The observation ${ }^{8}$ of progressive pancreatic duct hyperplasia in diabetes is compatible with the operation of common aetiological factors, genetic or environmental or both. On the other hand there is no evidence to support the hypothesis that bovine or porcine insulin, which have been shown to be both antigenic and teratogenic, ${ }^{9}$ are also carcinogenic for the pancreas in man.

\section{The Nation's Health}

Though 1969 produced the lowest infant mortality and stillbirth rates ever recorded in England and Wales, some other indices of health give reason for disquiet.

In his latest annual report ${ }^{1}$ the Chief Medical Officer of the Department of Health and Social Security records the expectation of life at 1 year old in 32 countries. The figures are mostly based on experience in the first half of the 1960s. In contrast to what is generally believed, England and Wales makes a remarkably poor showing. In no fewer than 17 countries males have a longer expectation of life. Among them are the Irish Republic, the Scandinavian countries, Switzerland, Spain, Bulgaria, East Germany, and Poland. For females five countries offer a longer expectation of life. They are France, Iceland, Netherlands, Norway, and Sweden. Prominent among the variety of reasons for British males' relatively low life expectancy must be the large number of deaths due to lung cancer from smoking of cigarettes. No doubt there are others-and in any case the figures for all the countries 'Chief Medical Officer of the Department of Health and Social Security,
Annual Report for the Year 1969, On the State of the Public Health. London, H.M.S.O., 1970. 
are clustered very closely around the age of 71 -but the ill effects of this habit are still strangely ignored.

While immunization has enabled some deadly diseases to be almost overcome-notably smallpox and diphtheriainfluenza stands out as one that can still cause dire epidemics. Last winter's epidemic, the C.M.O. reports, probably caused as high a sickness rate and mortality as in any comparable period since the 1930s. Not surprisingly the general public have been asking their doctors for some years past about vaccination against this disease, but even now there seems little positive to offer. Killed virus vaccines are not effective enough to warrant their general use to control spread of the disease, says the C.M.O. Live vaccine has been widely used in the U.S.S.R., "but, so far as is known, without yielding clear evidence of reliable protection." Consequently, vaccines remain "very much an individual matter for doctors and their patients."

In some unexpected ways the nation's health has improved. For instance, over the past 10 years a striking fall in mortality has been recorded for hypertensive diseases, peptic ulcer, and suicide. Teeth are better cared for than they used to be, but more in the south than the north. And measles and whooping cough seem to be coming under control as a result of the recently introduced vaccines. Against that must be set the sad story of gonorrhoea, regarded by optimists in the early 1950 s as about to be eliminated by antibiotics. The C.M.O. now reports that the total of reported cases in 1969 is higher than the previous peak of 1946, and the prevalence of the disorder is increasing at an accelerating pace.

\section{Maternal Phenylketonuria}

An aspect of phenylketonuria which has recently received attention is the damaging effect on the fetus of the untreated disease in the pregnant mother. C. E. Dent ${ }^{1}$ first pointed to this possibility in 1956. In 1963 C. C. Mabry and colleagues ${ }^{2}$ described three untreated phenylketonuric women who had 1,5 , and 8 children respectively. The seven children who survived were all mentally retarded, though none of the five who were investigated was found to have phenylketonuria. Similar cases were then reported, ${ }^{3-5}$ and Mabry and his colleagues added three more families. ${ }^{6}$ Recently several authors $^{5}$ 7-9 have shown that untreated maternal phenylketonuria is associated not only with mental retardation in the offspring but with intrauterine and postnatal retardation of growth, microcephaly, and skeletal, cardiac, and ocular

\footnotetext{
1 Dent, C. E., Ross Pediatric Research Conferences, 1957, 23, 32.

2 Mabry, C. C., Denniston, J. C., Nelson, T. L., and Son, C. D., New England fournal of Medicine, 1963, 269, 1404.

Coffelt, R. W., Pediatrics, 1964, 34, 889

Richards, B. W., Lancet, 1964, 1, 829.

Williams, R., Medical fournal of Australia, 1968, 2, 216 Mabry, C. C., Denniston, J. C., and Coldwell, J. G., New England Fournal of Medicine, 1966, 275, 1331

7 Stevenson, R. E., and Huntley, C. C., Pediatrics, 1967, 40, 33.

${ }^{-}$Frankenburg, W. K., et al., fournal of Pediatrics, 1968, 73, 560

Fisch, R. O., Doeden, D., Lansky, L. L., and Anderson, J. A., American Fournal of Diseases of Children, 1969, 118, 847.

o Partington, M. W., Canadian Medical Association fournal, 1963, 86, 736.

11 Woolf, L. I., et al., Lancet, 1961, 2, 464.

12 Perry, T. L., Hansen, S., Tischler, B., Bunting, R., and Diamond, S., New England fournal of Medicine, 1970, 282, 761 .

13 Yu, J. S., and O'Halloran, M. T., Lancet, 1970, 1, 210.

14 Allan, J. D., and Brown, J. K., in Some Recent Advances in Inborn Errors of Metabolism, ed. K. S. Holt and V. P. Coffey, p. 14. Edinburgh,
} Livingstone, 1968 . malformations, as well as repeated miscarriages in the mother.

The effect of maternal phenylketonuria on the fetus is not fully known. M. W. Partington ${ }^{10}$ has described a typical phenylketonuric woman who gave birth to two retarded children and one of normal intelligence. And L. I. Woolf and colleagues" reported two sisters with "atypical phenylketonuria" who produced normal children, but the serum levels of phenylalanine in these women were below $10 \mathrm{mg}$. per $100 \mathrm{ml}$. There may be a critical level of phenylalanine in maternal blood below which the fetus is not damaged, or perhaps some fetuses have a built-in biochemical resistance to the ill effects of phenylalanine, as has been suggested by T. L. Perry and colleagues ${ }^{12}$ to explain why some phenylketonurics have unimpaired intelligence.

The successful treatment of phenylketonuria in infancy and childhood has enabled girls to grow up into women who are likely to marry, but it is most improbable that dietetic treatment will have been maintained into adolescence. J. S. Yu and $M$. T. O'Halloran ${ }^{13}$ have suggested that pregnancy in the known phenylketonuric should be planned and the dietetic treatment should be started before the beginning of pregnancy. The nearest approach to this form of treatment so far is in the report by J. D. Allan and J. K. Brown. ${ }^{14}$ They maintained a known phenylketonuric woman (who had already had three mentally retarded children) on a low-phenylalanine diet for the last five months of pregnancy: the infant was reported to be developing normally up to the age of 9 months, when their report was made.

But the situation is more complex than this, for the fetus can be damaged when pregnancy occurs in women of normal intelligence with unsuspected phenylketonuria. ${ }^{3}{ }^{9}$ It is therefore important that the female sibs of all phenylketonuric patients should be investigated before marriage, regardless of intelligence. Similarly all women should be tested for phenylketonuria who have produced one or more mentally retarded children in whom there is no obvious cause for the retardation. So too perhaps should those who have had repeated miscarriages or who have produced children with skeletal, cardiac, or ocular malformations. The logical outcome of all these observations is that screening for phenylketonuria should become part of every antenatal examination. Now that the screening of the newborn infant has been generally accepted, an extension to the antenatal clinic should not be too difficult.

\section{Self-certification?}

For three weeks in June of this year the majority of family doctors refused to sign national insurance certificates. During the period new claims for both sickness and industrial injury benefit were about 75,000 fewer than usual for the time of year. This sharp drop is in marked contrast to the rising trend in claims shown in the latest annual report of the Department of Health and Social Security ${ }^{1}$-in 1969 there was a rise of nearly $8 \%$ over the previous year to a level exceeding 12 million claims.

Can this be cited in support of the argument that family doctors should no longer be required to sign certificates on the ground that it would free them from a non-clinical chore while at the same time providing the Exchequer with substantial savings? On the evidence available, probably not. 